Original Article

\title{
DIETARY SUPPLEMENTATION OF NATURAL AND SYNTHETIC PRODUCTS REDUCES ANXIETY IN M ICE AGAINST ELECTRON BEAM RADIATION INDUCED OXIDATIVE STRESS
}

\author{
Suchetha Kumari N. ${ }^{1} \&$ Madhu L.N. ${ }^{2}$ \\ ${ }^{1}$ Professor, Department of Biochemistry, K.S. Hegde Medical Academy, Nitte University, Mangalore - 575018 , \\ ${ }^{2}$ Department of Biochemistry, St. Aloysius College, M angalore - 575 003, Karnataka, India. \\ Correspondence : \\ Suchetha Kumari N. \\ Professor, Department of Biochemistry, K. S. Hegde M edical Academy, Nitte University, M angalore - 5750 18, Karnataka, India. \\ E-mail : suchethakumarin@gmail.com
}

\section{Abstract:}

Background: Due to the increased use of ionizing radiation in various aspects of human life, free radical formation is greatly augmented during exposure. This causes damage to the central nervous system. The natural and synthetic products have proven therapeutic benefits. Nardostachys jatamansi, an indigenous medicinal plant showed to promote physical and mental health augment resistance of the body against disease and has shown potent antioxidant activity. 1, 2, 4 triazole derivatives are the synthetic organic compound which has various pharmacological activities.

Objectives : To study the anxiolytic and protective effect of 100mg of ethanolic extract of Nardostachys jatamansi (NJE) and triazole (AMT) on the mice exposed to 6Gy Electron beam radiation (EBR).

Materials and M ethods : The animals were treated with $100 \mathrm{mg}$ of NJE and Triazole for 15 days before radiation exposure. The anxiety status of animals observed once for every 3 days during experiment period. The biochemical estimations were carried 15 days after irradiation in mice brain homogenate.

Results and Conclusion : Treatment of mice with phytochemical and synthetic compound before irradiation caused a significant depletion in anxiety, lipid peroxidation followed by significant elevation in catalase, total antioxidant, and total protein. Our results indicate that the protective activity of NJE and triazole on radiation induced anxiety and oxidative stress may be due to free radical scavenging and increased antioxidant level in mice.

Keywords : Free radicals, Anxiety, Electron beam, Oxidative stress.

\section{Introduction:}

Exposure to ionizing radiation increases production of Reactive oxygen species and can lead irradiated cells into the state of oxidative stress, which has been implicated in an enormous variety of natural and pathological processes

${ }^{[1]}$. Oxidative stress on nervous tissue can produce damage by several interacting mechanisms. This may alter variety of central nervous system

\begin{tabular}{|c|}
\hline Access this article online \\
\hline Quick Response Code \\
\hline
\end{tabular}

(CNS) - mediated processes $^{[2]}$.

Anxiety disorders are the highly prevalent psychiatric disorders, affecting an estimated $25 \%$ of the adult population at some point during their lifetime ${ }^{[3]}$. It has been demonstrated that flavonoids possess mild sedative and anxiolytic effects. The naturally occuring flavonoids and their synthetic derivatives have been reported to selectively bind to the central benzodiazepine receptors, and to exert anxiolytic and other benzodiazepine-like effects in animals ${ }^{[4]}$.

Nardostachys jatamansi (family Valerianaceae), an indigenous medicinal plant induces in organism a state of resistance against stress. It helps to promote physical and mental health augment resistance of the body against disease and has shown potent antioxidant activity. It has also shown marked tranquillizing activity, as well as hypotensive, hypolipidemic, anti-ischemic, antiarrhythmic, hepatoprotective, anticonvulsant, 
neuroprotective activities ${ }^{[5.7]}$.

Triazoles are the important class of heterocyclic compounds having three nitrogen atoms. They are of two types, 1, 2, 3 triazoles and 1, 2, 4 triazoles. Various 1, 2, 4 triazoles and its derivatives are found to be linked with diverse pharmacological activities. Compounds containing 1,2,4-triazole ring have been reported to possess different biological activities such as antimicrobial ${ }^{[8]}$, antifunga $\mathrm{I}^{[9]}$, anti-inflammatory ${ }^{[10]}$, antiviral ${ }^{[11]}$, anticancer ${ }^{[12,13]}$, analgesic ${ }^{[14]}$, and anticonvulsant ${ }^{[15]}$ activity depending on the substituent in the ring system.

In the present study, the potential and modulatory role of Nardostachys jatamansi and Triazole derivative has been explored on radiation induced changes in anxiety and oxidative stress in mice.

\section{Materials and Methods:}

\section{Plant material and preparation of extract:}

The plant material i.e. rhizome powder of Nardostachys jatamansi was collected from GENUINE chemical co, M umbai. This powder was extracted with $95 \%$ ethanol at room temperature, concentrated in reduced temperature and pressure on rotary evaporator and stored at $4^{\circ} \mathrm{C}$.

\section{Chemistry}

4-amino-5-mercapto 1, 2, 4-triazoles was prepared according to the methods proposed in literature ${ }^{[16]}$.

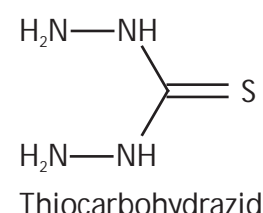

Thiocarbohydrazide

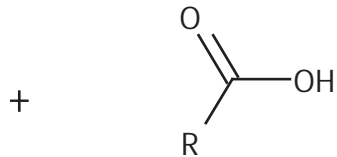

alkanoic acid $65^{\circ} \mathrm{C} / 1.30 \mathrm{~min}$<smiles>[R]c1nnc(S)n1N</smiles>

4-amino-5-mercapto-3-substituted-1, 2, 4-triazole

\section{Animal care and handling:}

Animal care and handling was carried out according to the guidelines set by WHO (World Health Organization; Geneva, Switzerland). The institutional animal ethical committee has approved this study. Swiss albino mice aged $6-8$ weeks and weighing $25 \pm 5 \mathrm{~g}$, taken from an inbred colony, was used for this study. The mice were maintained under controlled conditions of temperature and light (light: $10 \mathrm{~h}$; dark: $14 \mathrm{~h}$ ). The animals were housed in a polypropylene cage containing sterile paddy husk (procured locally) as bedding throughout the experiment. They were provided standard mouse feed and water ad libitum.

\section{Irradiation :}

The irradiation work was carried out at Microtron centre, Mangalore University, Mangalore, Karnataka, India. The animals were restrained in well-ventilated perspex boxes and exposed to whole-body electron beam at a distance of $30 \mathrm{~cm}$ from the beam exit point of the Microtron accelerator at a dose rate of $72 \mathrm{~Gy} / \mathrm{min}$.

\section{Experimental protocol:}

The following groups of animals were used.

Group I: Control

Group II: Animals were exposed to 6Gy (sub-lethal dose) electron beam radiation (EBR).

Group III: Animals were received on N.jatamansi extract (100mg/kg body weight) orally for 15 days (The required amount of NJE was dissolved in 10\%DM SO). 1 hour after final dose animals were exposed to 6Gy EBR.

Group IV: Animals were received on triazole (AMT) (100mg/kg body weight) orally for 15 days (The required amount of AMT was dissolved in dist water). 1 hour after final dose animals were exposed to 6Gy EBR.

\section{Elevated Plus Maze M odel ${ }^{[17]}$}

The plus-maze apparatus, consisting of two open arms (16 $x 5 \mathrm{~cm})$ and two closed arms $(16 \times 5 \times 12 \mathrm{~cm})$ having an open roof. Both the drugs $(100 \mathrm{mg} / \mathrm{kg}$ ) were administered orally for 15 days once daily and the last dose was given on the 15th day, 60 min prior to radiation exposure. The mouse 
was placed at the center of the maze with its head facing the open arm. During the 5 min experiment, the behavior of the mouse was recorded as: the number of entries into the open or closed arms and time spent by the mouse in each of the arms. An arm entry was defined as the entry of all four paws into the arm. The animals were observed once for every 3 days during experiment period.

\section{Dissection and homogenization of Brain}

On $15^{\text {th }}$ day post irradiation, animals were scarified by cervical dislocation, followed by decapitation. The whole brains were removed and $10 \%(\mathrm{~W} / \mathrm{V})$ tissue homogenates were prepared in $0.4 \mathrm{M}$ phosphate buffer pH7.0, centrifuged for $25 \mathrm{~min}$ at $5000 \mathrm{rpm}$ at $4^{\circ} \mathrm{C}$ and the supernatant was used for estimation of the following biochemical assays.

\section{Lipid peroxidation (LPX):}

LPx was measured by the method of Beuege and Aust ${ }^{[18]}$. Briefly, serum was mixed with TCA-TBA-HCl and was heated for $15 \mathrm{~min}$ in a boiling water bath. After centrifugation the absorbance was recorded at $535 \mathrm{~nm}$ using a UV-Vis double beam spectrophotometer. The LPX has been expressed as M elondialdehyde in $\mu \mathrm{M}$ per liter.

\section{Total antioxidant capacity:}

Total antioxidant capacity of serum was determined by the phosphomolybdenum method as described by Prieto et al. ${ }^{[19]}$. The serum was precipitated with 5\% TCA, it was then made to react with TAC reagent containing phosphomolybdenum at $95^{\circ} \mathrm{C}$ for $90 \mathrm{~min}$. The absorbance was read at $695 \mathrm{~nm}$.

\section{Catalase activity:}

Catalase activity in RBC was measured spectrophotometrically as previously described ${ }^{[20]}$. The method is based on the fact that catalase causes breakdown of $\mathrm{H}_{2} \mathrm{O}_{2}(30 \mathrm{mM})$. The $\mathrm{H}_{2} \mathrm{O}_{2}$ was mixed in $3 \mathrm{ml}$ of Phosphate buffer ( $\mathrm{pH} 7.0)$ and then $50 \mu \mathrm{l}$ of 1:20 diluted erythrocyte was added and the changes in absorbance at $240 \mathrm{~nm}$ were recorded up to $2 \mathrm{~min}$ at the interval of $15 \mathrm{sec}$. The enzyme activity was expressed as Units $\mathrm{mg} \mathrm{Hb}^{-1}$.

\section{Total protein}

The total protein in the brain tissue was estimated by biuret method $^{[21]} .20 \mu$ l of tissue homogenate was mixed with $1 \mathrm{ml}$ of reagent. 5 min after incubation the absorbance was read at $546 \mathrm{~nm}$. The results were expressed as gram protein per $100 \mathrm{ml}$ of $10 \%$ homoginate.

\section{Statistical analysis}

Results were expressed as Mean \pm standard deviation. Comparison between the control and treated groups were performed by analysis of variance (ANOVA), followed by student's t-test. In all the test, criterion for statistical significance was $\mathrm{P}<0.05$.

\section{Results:}

The test conducted in the elevated plus maze had shown positive results. The irradiated animals showed spending more time in closed arm than the open arm. The time spending in closed arm can be directly considered as the level of anxiety. We also observed, there was an increase in level of anxiety from the day of irradiation to the $15^{\text {th }}$ day after irradiation. The treatment groups, both NJE and Triazole have showed decreased level of anxiety when compared to irradiated group (Table 1).

The irradiation of mice to 6Gy of electron beam radiation induces lipid peroxidation. The irradiated group had showed significant increased Melondialdehyde (MDA) level and decrease in the catalase, total protein and antioxidant level. But the pre supplementation of NJE and AMT before irradiation had showed the decreased level of lipid peroxidation and increased level of catalase, total protein (Graph 1), antioxidant when compared to irradiated group (Table 2). This proves that the synthetic and natural product with antioxidant property helps in lowering the oxidative stress in irradiated mice.

\section{Discussion :}

Anxiety may be regarded as a particular form of behavioral inhibition that occurs in response to environmental events that are novel. It has been established that there are lot of plant secondary metabolites being employed in the treatment of psychotic disorders especially for anxiety in 
Table 1 : Effect of NJE and AMT on animals in EPM model

\begin{tabular}{|l|c|c|c|c|}
\hline & \multicolumn{2}{|c|}{ No.of entries to open arm } & \multicolumn{2}{c|}{ No.of entries to closed arm } \\
\hline & Before Irradiation & $\begin{array}{c}\text { 15th day after } \\
\text { irradiation }\end{array}$ & Before Irradiation & $\begin{array}{c}\text { 15th day after } \\
\text { irradiation }\end{array}$ \\
\hline 6Gy Irradiated animal & $12.50 \pm 2.10$ & $2.50 \pm 1.09$ & $9.90 \pm 1.10$ & $5.53 \pm 1.50$ \\
\hline NJE treatment & $10.75 \pm 2.15$ & $6.80 \pm 2.55$ & $11.12 \pm 2.10$ & $5.00 \pm 1.75$ \\
\hline AMT & $12.10 \pm 2.70$ & $7.10 \pm 1.25$ & $10.25 \pm 1.55$ & $6.23 \pm 1.65$ \\
\hline
\end{tabular}

Values are expressed as M ean \pm Standard deviation. $P \varangle 0.05$ as compared to treated group with 6 Gy irradiated radiation group.

\begin{tabular}{|l|c|c|c|c|}
\hline & Control & 6 Gy irradiation & $\begin{array}{c}\text { NJE treatment } \\
+6 G y \text { irradiation }\end{array}$ & $\begin{array}{c}\text { AMT treatment } \\
+6 G y \text { Irradiation }\end{array}$ \\
\hline MDA $(\mu \mathrm{M} / \mathrm{g}$ tissue $)$ & $3.74 \pm 0.51$ & $14.77 \pm 7.89^{*}$ & $10.30 \pm 3.20^{* *}$ & $10.40 \pm 4.25^{* *}$ \\
\hline Catalase $(\mathrm{U} / \mathrm{mg}$ protein) & $8.35 \pm 2.10$ & $2.11 \pm 1.09^{*}$ & $7.23 \pm 2.15^{* *}$ & $5.45 \pm 1.11^{* *}$ \\
\hline TAC $(\mu \mathrm{g} / \mathrm{ml} 10 \%$ homoginate $)$ & $88.80 \pm 31.30$ & $39.80 \pm 11.12^{*}$ & $82.25 \pm 10.33^{* *}$ & $69.45 \pm 9.35^{* *}$ \\
\hline
\end{tabular}

Values are expressed as $M$ ean \pm Standard deviation. $* * P \varangle 0.01$ as compared to the 6 Gy irradiated radiation group. $* P \varangle 0.05$ as compared to $6 \mathrm{~Gy}$ irradiated radiation group with control.

Graph 1 : Effect of Treatment with NJE and AMT on Total Protein Levels in Brain of Mice Exposed To Electron Beam Radiation

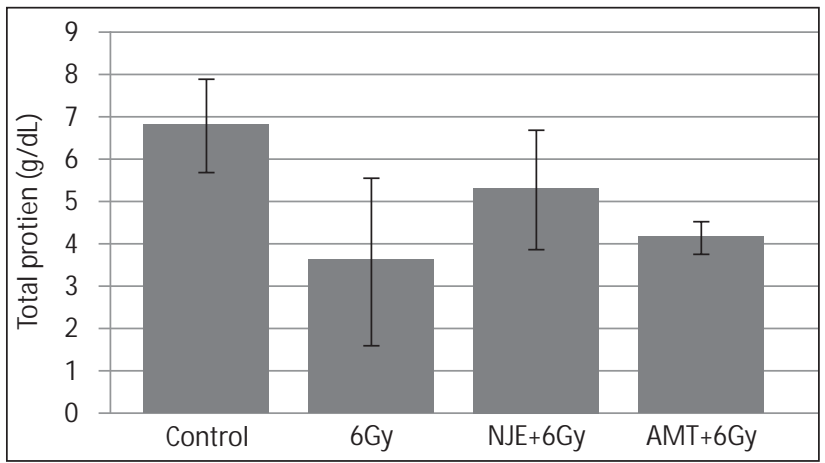

Values are expressed as Mean \pm Standard deviation. $\mathrm{P} \varangle 0.05$ as compared to treated group with $6 \mathrm{~Gy}$ irradiated radiation group.

traditional medicine practice. The results of present study show that extract of Nardostachys jatamansi exhibited anxiolytic activity. Recently, several herbal constituents have been reported to possess anxiolytic effects through animal models of anxiety ${ }^{[22]}$, such as Spondias mombin ${ }^{[23]}$, Trigonella foenum-graecum ${ }^{[24]}$, Sapindus mukorossi ${ }^{[25]}$, Panax ginseng ${ }^{[26]}$. Other than the natural products synthetic compounds such as Nitrazepam ${ }^{[27]}$, Baicalin ${ }^{[28]}$ have also showed anxiolytic property.

A single whole-body exposure of mammals to ionizing radiation results in a complex set of syndromes whose onset, nature and severity are a function of both total radiation dose and radiation quality. At the cellular level, ionizing radiation can induce damage in biologically important macromolecules such as DNA, proteins, lipids and carbohydrates in various organs ${ }^{[29,30]}$.

Nardostachys jatamansi root extract has shown both in vitro and in vivo antioxidant property ${ }^{[31]}$. It attenuates stress induced elevation of biochemical changes such as membrane lipid peroxidation, elevated NO production in brain as well as stomach, levels of antioxidant enzymes like catalase, which are consistent with its anti stress properties. The similar mechanism might be the reason for the protection of mice against electron beam radiation induced lipid peroxidation followed by oxidative stress.

Depletion of intracellular catalase, total protein and total antioxidant level has been implicated as one of the causes of radiation induced damage, while increased levels of this are responsible for the radioprotective action. Pre supplementation of NJE and AM Thelped to restore the TP, TA and catalase level when compared to the concurrent irradiation control group. This inhibits the radiation induced lipid peroxidation, thereby protecting against radiation-induced damage.

\section{Conclusion :}

From the above observations the study conclude that ethanolic extract of Nardostachys jatamansi and synthetic triazole compound possesses anxiolytic activity, also it showed protective effect against radiation induced oxidative stress. However further studies are required to know the exact mechanism of action. 


\section{References:}

1. Uma Devi P, Nagarathnam A, Sathish Rao BS. Introduction to radiation biology. B.I. Churchill Livingstone Pvt. Ltd., New Delhi. 2000.

2. Barry Halliwell. Reactive Oxygen Species and the Central Nervous System. Journal of Neurochemistry 1992;59:1609-1623.

3. Kjernised KD, Bleau P. Long-term goals in the management of acute and chronic anxiety disorders. Can J Psychiatry 2004;49(suppl1):5165

4. Medina JH, Viola H, Wolfman C, Marder M, Wasowski C, Calvo D, Paladini AC. Overview - Flavonoids a new family of benzodiazepine receptor ligands. Neurochem Res 1997;22:419-425

5. Rao VS, Rao A, Karanth KS. Anticonvulsant and Neurotoxicity Profile of Nardostachys jatamansi in Rats. Journal of Ethanopharmacology 2005; 102:351-356.

6. Arora RB, Singh KP, Das PK, M istry PN. Prolonged Hypotensive Effect of an Essential oil of $\mathrm{N}$. jatamansi. Archives Internationales de Pharmacodynamieet de Therapie 1958;113:367-376.

7. Vinutha B, Prashanth D, Salma K, Sreeja SL, Pratiti D, Padmaja R, S. Radhika, A. Amit, K. Venkateshwralu, M. Deepak. Screening of Selected Indian Medicinal Plants for Acetylcholinesterase Inhibitory Activity. Journal of Ethnophamacology 2007;109:359-363.

8. Turan-Zitouni G, Kaplancikli ZA, Yildiz M T, Chevallet P, Kaya D. Synthesis and antimicrobial activity of 4-phenyl/cyclohexyl-5-(1-phenoxyethyl)3-[N-(2-thiazolyl) acetamido]thio-4H-1,2,4-triazole derivatives. Eur ] Med Chem 2005;40:607-13.

9. Papakonstantinou-Garoufalias S, Pouli N, Marakos P, ChytyroglouLadas A. Synthesis antimicrobial and antifungal activity of some new 3substituted derivatives of 4-(2,4-dichlorophenyl)-5-adamantyl-1H1,2,4-triazole. II Farmaco 2002;57:973-977.

10. Palaska E, Sahin G, Kelicen P, Durlu NT, Altinok G. Synthesis and antiinflammatory activity of 1- acylthiosemicarbazides, 1, 3, 4oxadiazoles, 1, 3, 4- thiadiazoles and 1, 2 ,4- triazoles- 3- thiones. II Farmaco 2002;57:101-107.

11. Hashem Al, Youssef AS, Kandeel KA, Abou-Elmalgd WS. Conversion of some 2(3H)-furanones bearing a pyrazolyl group into other heterocyclic systems with a study of their antiviral activity. Eur J Med Chem. 2007:42:934-939.

12. Holla BS, Sarojini BK, Rao BS, Akberali PM, Suchetha Kumari N, Shetty V. Synthesis of some halogen-containing 1,2,4-triazolo-1,3,4thiadiazines and their antibacterial and anticancer screening studies - Part I. II Farmaco 2001;56:565-570.

13. Bekircan O, Kahveci B, Kucuk M. Synthesis and Anticancer Evaluation of Some New Unsymmetrical 3, 5-Diaryl-4H-1, 2, 4-Triazole Derivatives. TurkJ Chem 2006;30:29-40.

14. Turan-Zitouni G, Kaplancikli ZA, Erol K, Kilic FS. Synthesis and analgesic activity of some triazole and triazolothiadiazines. II Farmaco 1991:54:218-223.
15. Chen J, Sun XY, Chai KY, Lee JS, Song MS, Quan ZS. Synthesis and anticonvulsant evaluation of 4-(4-alkoxylphenyl)-3-ethyl-4H-1,2,4triazoles as open-chain analogues of 7-alkoxyl-4,5dihydro[1,2,4]triazolo[4,3-a]quinolines. Bioorg Med Chem 2007;15:6775-6781.

16. Ried JR, Heindel ND. Improved synthesis of 5-substituted-4- amino-3mercapto-(4H)-1, 2, 4-triazoles. J Heterocycl Chem 1976;13:925-926.

17. Yadav AV, Kawale LA, Nade VS. Effect of M orusalba L. (mulberry) leaves on anxiety in mice. Indian Journal of Pharmacol 2008;40:32-36.

18. Beuege JA and Aust SD. Microsomal Lipid Peroxidation. Methods in Enzymology 1978;30:302-10.

19. Prieto P, Pineda M. Spectrophotometric Quantitation of Antioxidant Capacity through the Formation of a Phosphomolybdenum Complex: Specific Application to the Determination of Vitamin E. Analytical Biochemistry 1991:269:337-341.

20. Aebi H. Catalase in vitro. Methods in Enzymology. (Colowick S.P, Kaplan N.O, ed) Acad. Press. Florida 1984;105:114-21.

21. Thomson L. clinical laboratory diagnostics. $1^{\text {st }}$ ed. Frankfurt: TH-Books Verlags-gesellschaft., 1998;644-7.

22. Beaubrum $G$ and Gray GE. A review of herbal medicines for psychiatric disorder. Psychiatr Serv 2000;51:1130-1134.

23. Ayoka AO, Akomolafe RO, Iwalewa EO Ukponmwan OE. Studies on the anxiolytic effect of spondias mombin I. (anacardiaceae) extracts. Afr J Trad CAM 2005;2(2):153

24. Dhananjaya DR, Vijay KS, Chandrashekar GP, M akhija IK, Shivakumara S. Anxiolytic activity of ethanolic extract of Trigonella foenumgraecum seeds. Archives of Applied Science Research 2011;3(1):91-95.

25. Avijit C, Amudha P, Geetha M, Surjit singh N. Evaluation of anxiolytic activity of methanolic extract of sapindus mukorossi gaertn in mice. International Journal of Pharma and Bio Sciences 2010;1(3):1-8.

26. Bhattacharya SK, M itra SK. Anxiolytic activity of Panax ginseng roots: an experimental study. J Ethanopharmacol 1991;34(1):87-92.

27. Venugopal reddy P, Kshama D. Intrastrain variations in anxiolytic effect of Nitrazepam in mice. Indian J Physiol Pharmacol 2006:50(3):309-312.

28. Xiuyan W, Jingyu Y, Chunfu W. Anxiolytic Effect of Baicalin in Mice. Asian Journal of Traditional M edicines 2006;1:3-4.

29. Jagetia GC, Baliga MS, Malagi KJ, Kamath MS. The Evaluation of the Radioprotective Effect of Triphala (an Ayurvedic rejuvenating drug) in the mice exposed to ?-radiation. Phytomedicine 2002;9:99-108

30. Jagetia GC, Baliga M S. An Ayurvedic Herbal Drug Imparts Protection to the Mice against the lethal Effects of Gamma-radiation: a Preliminary Study. Nahrung 2002;46:332-6.

31. Lyle N, Bhattacharyya D, Sur TK, M unshi S, Paul S, Chatterjee S, Gomes A. Stress Modulating Antioxidant Effect of Nardostachys jatamansi. Indian Journal of Biochemistry and Biophysics 2009;46;93-98. 